\title{
Electromobility - the Importance of Power Quality and Environmental Sustainability
}

\author{
Aleksander Chudy ${ }^{1 *}$, Paweł Artur Mazurek ${ }^{1}$ \\ ${ }^{1}$ Institute of Electrical Engineering and Electrotechnologies, Faculty of Electrical Engineering and Computer \\ Science, Lublin University of Technology, Nadbystrzycka 38D, 20-618, Lublin, Poland \\ * Corresponding author's e-mail: a.chudy@pollub.pl
}

\begin{abstract}
Electric vehicles (EVs) play a significant role in a gradual shift towards low-carbon society. However, the impact of electromobility on a power system includes different power quality problems that need to be mitigated. Power Quality Analyzer SONEL PQM-700 was used for the measurement and analysis of the power quality parameters during slow charging (at $\sim 11 \mathrm{~A}, \sim 8,3 \mathrm{~A}$ and $\sim 5,5 \mathrm{~A}$ ) of a BMW i3 electric vehicle. The read-out mode of the device was considered. The state of EV charge was $30 \%$. The measurements focused on the values of supply voltage, drawn current, harmonics, values of active, reactive and apparent power. In this study, type 2 connector was used to charge the EV. The power quality parameters during the BMW i3 charging were within limits, not a single parameter was exceeded. Additionally, the current state of electric vehicle charging methods and EV charging infrastructure was described and power conditioning solutions were presented.
\end{abstract}

Keywords: electromobility, electric vehicle charging, power quality, environmental sustainability

\section{INTRODUCTION}

Production of high quality electric power is one of the major challenges of modern power engineering. Unfortunately, this is difficult in the case of an increasing number of non-linear receivers. The quality of energy has an impact on the safe and reliable operation of computers and industrial equipment. Possible losses of industrial productivity or equipment failures are a huge waste of time and money, which translate into high demands on the quality of electricity by the industrial and public sectors.

One of the primary sources of global climate change and $\mathrm{CO}_{2}$ pollution is the transport industry. The European Union has recently undertaken a detailed revision of its energy model. Thus, a progress towards a low-carbon society is needed in order to achieve this objective. A car that is driven at least in part by electric force that is obtained from electric and traction motors is called an electric vehicle (EV). For a gradual shift, renewable energy sources and electric vehicles play a significant role. First electrical vehicles were built in nineteenth century; however, their usage seems to be more justified and serious at present, due to their improved range and efficiency. Typical range of an EV ranges from $150 \mathrm{~km}$ to $250 \mathrm{~km}$ but there are also more advanced models like Tesla Model $3(498 \mathrm{~km})$ (Colmenar-Santos et al., 2019; https://www.tesla.com/model3, 2019; Nikitha et al., 2017).

The society is in the need of the sustainable transport and it can be achieved with the usage of wind and solar power. Electric way of powering a vehicle seems to be the only reasonable way in the future, as it contributes to lower greenhouse gases emissions.

The energy efficiency of electric vehicles is improved as they depend on electricity rather than fuel combustion. This is the reason why they contribute to various transport policy objectives. A gradual shift towards electric vehicles can be observed, promoted by policy-makers as more ecological than internal combustion engine vehicles (ICEVs). It can be concluded that the internal 
combustion engine vehicles are responsible for a substantial portion of air pollution. (approximately $16 \%$ of the total $\mathrm{CO}^{2}$ emitted by human). It worsens the air quality and wreaks havoc on the human health (Khalid et al., 2019).

However, the impact of electromobility on the power system includes voltage instability, increased peak demand and different power quality problems that need to be mitigated (Tiano et al., 2018). When integrated with the utility grid, battery electric vehicles and plug-in hybrid electric vehicles are treated as a load in a power system. The load is not the only one contributor to lower power quality (Broy and Sourkounis, 2011). A large amount of EVs charging stations that use power electronic circuits, produce harmonics, impact the voltage profile, and ultimately impact the power quality. The operation of an electric charger contributes to the decrease of the power factor of an AC grid. This is becoming a major concern for power companies (Jiang et al., 2014). Fig.1. presents the positive and negative impact of EVs.

\section{CURRENT STATE OF ELECTRIC VEHICLE CHARGING METHODS AND EV CHARGING INFRASTRUCUTRE}

There are two main types of electric vehicle charging infrastructures. Conductive and non-conductive (wireless power transfer) charging can be distinguished. The latter one is considered a novel charging technology. Capacitive coupled power transfer (dynamic wireless charging - charging while driving) and inductive power transfer (quasi-dynamic, dynamic and static wireless charging) are primarily used for EVs. A distinctive advantage of wireless charging is the convenience of the electric vehicle user. It could mitigate the problems connected with short battery life, limited capacity of the battery and initial costs. Instead of deeply discharging the battery, one can often recharge it at the parking lot, home, at work, during shopping, or even while standing at the traffic lights. It is also possible to build charging strips on motorways, which allows charging while driving. For this reason, inductive charging can significantly reduce the need for the fast charging infrastructure. Furthermore, the size of non-conductive chargers is smaller than of conductive chargers. The disadvantages include relatively low efficiency (due to loosely coupled effect), low power density, production complexity and high cost. It is still an innovative technology that needs more research to become more advanced and competitive with conductive charging (Khalid et al., 2019; Zhang et al., 2019). More information about non-conductive charging can be found in (Gao et al., 2016; Hou et al., 2016; Jang, 2018; Machura and Li, 2019; Sarker et al., 2016; Zhang and Mi, 2016).

The most popular and at the same time the most advanced method of EV charging is conductive charging. This technique is more efficient than wireless EV charging. The on-board and off-board charging infrastructures can be

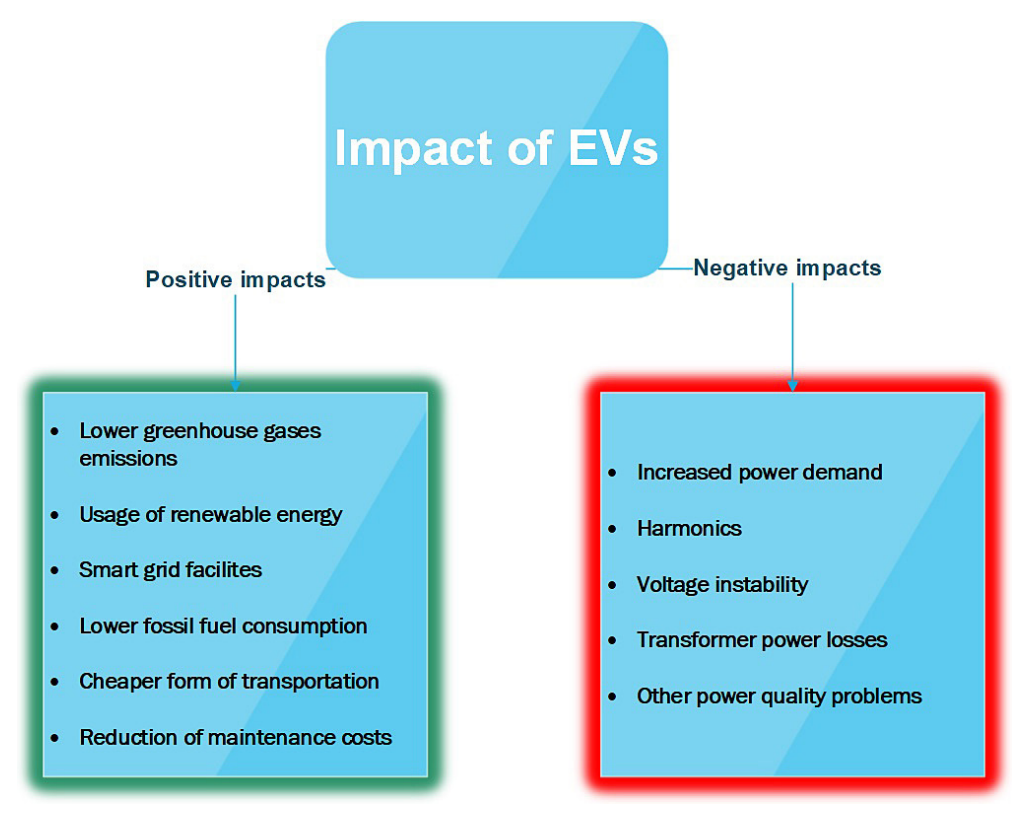

Figure 1. Positive and negative impacts of EVs (Karmaker et al., 2019) 
distinguished. The International Electrotechnical Commission - IEC, The Institute of Electrical and Electronics Engineers - IEEE, The Infrastructure Working Council - IWC and Society of Automotive Engineers - SAE, are main organizations that have been taking part in standardizing the charging requirements for EVs for years. The SAE standard - Electric Vehicle and Plug in Hybrid Electric Vehicle Conductive Charge Coupler J1772 has become a common standard in North America. SAE sets out several points related to the charging protocols, systems and electrical specifications. Charging stations are also classified according to their power level. The classification of charging power levels relies on the output power that an electric vehicle charger is able to give to the battery of an EV. What is more, it requires taking into account the power levels achievable at household and commercial utilities and industrial supply. The J1772 standard characterizes 3 power levels (González et al., 2019; Nikitha et al., 2017; Spöttle et al., 2018).

EV charging stations and all equipment connected with EV charging in the countries that are members of the European Union must be designed in accordance with IEC 61851 and IEC 62196 standards (Can et al., 2016; Spöttle et al., 2018).

IEC 61851-1 defines four modes of EV charging. They characterize the protocol of the communication between charging stations and EVs. Table 1. shows a general overview of the EV charging modes in accordance with IEC 61851-1.
The higher the mode, the better it is for a customer as is it connected with faster charging. However, it is also related to higher energy demand, possible electrical upgrades and higher costs (Spöttle et al., 2018).

The International Electrotechnical Commission with its IEC 62196-2 standard, has also described three types of sockets-outlets (Falvo et al., 2014; Ferwerda et al., 2018):

- Type 1 - used in the USA and Japan (single phase systems), developed by Yazaki (SAE J1772/2009 standard),

- Type 2 - used in Europe (single and three phase systems), developed by Mennekes (VDE-AR-E 2623-2-2 standard),

- Type 3 - used in France and Italy (single and three phase systems), developed by the EV plug Alliance. This type was abandoned in 2012.

There are also other connectors that are not mentioned in IEC 62196-2 standard (Ferwerda et al., 2018; Hanauer, 2018):

- CHAdeMO also known as Type 4 with maximum power level of $50 \mathrm{~kW}$, developed in Japan, used in Japan and Europe that allows slow and fast charging,

- Combined Charging System (CCS), Type 2 and Combo 2 connector that allows slow AC charging (mode 3$)$ or fast DC charging (mode 4),

- Tesla Charger and Supercharger, international connector for slow and fast charging, respectively

Table 1. Overview of EV charging modes in accordance with IEC 61851-1 (Can et al., 2016; González et al., 2019; IEC 61851-1, 2017; Spöttle et al., 2018)

\begin{tabular}{|c|c|c|c|c|}
\hline Characteristic & $\begin{array}{l}\text { Mode } 1 \\
\text { (slow charging) }\end{array}$ & $\begin{array}{c}\text { Mode } 2 \\
\text { (slow charging with an } \\
\text { in-cable protection) }\end{array}$ & $\begin{array}{c}\text { Mode } 3 \\
\text { (slow or fast charging) }\end{array}$ & $\begin{array}{c}\text { Mode } 4 \\
\text { (fast charging with } \\
\text { an external charger) }\end{array}$ \\
\hline EV charge voltage & $\begin{array}{c}\mathrm{AC} ; 250 \mathrm{~V} 1 \mathrm{~F} ; 480 \mathrm{~V} \\
3 \mathrm{~F}\end{array}$ & $\begin{array}{c}\mathrm{AC} ; 250 \text { V } 1 \mathrm{~F} ; 480 \\
\text { V } 3 \mathrm{~F}\end{array}$ & $\begin{array}{l}\mathrm{AC} ; 250 \mathrm{~V} 1 \mathrm{~F} ; \\
480 \vee 3 \mathrm{~F}\end{array}$ & $\mathrm{DC} ; \leq 1000 \mathrm{~V}$ \\
\hline $\begin{array}{l}\text { Maximum current (steady } \\
\text { state) }\end{array}$ & $\leq 16 \mathrm{~A}$ & $\leq 32 \mathrm{~A}$ & $\leq 32 \mathrm{~A} / \leq 250 \mathrm{~A}$ & $400 \mathrm{~A}$ \\
\hline $\begin{array}{l}\text { Power [kW] (applied to } \\
\text { Mennekes Type 2) }\end{array}$ & $3.7-11$ & $7.4-22$ & $14.5-43.5$ & $38-170$ \\
\hline $\begin{array}{l}\text { Communication between } \\
\text { the station and the EV }\end{array}$ & No communication & $\begin{array}{l}\text { Control signal and } \\
\text { proximity }\end{array}$ & $\begin{array}{l}\text { Control signal and } \\
\text { proximity }\end{array}$ & $\begin{array}{l}\text { Control signal and } \\
\text { protections, CAN } \\
\text { protection and others }\end{array}$ \\
\hline $\begin{array}{l}\text { On-Board energy } \\
\text { conversion }\end{array}$ & Yes & Yes & Yes & No \\
\hline Connector & $\begin{array}{c}\text { Type A, Nema 1/ Type } \\
\text { F Schuko }\end{array}$ & SAE J1772, Mennekes & $\begin{array}{c}\text { SAE J1772, } \\
\text { Mennekes, CCS, } \\
\text { Scame, GB/T 20234-2 }\end{array}$ & ChAdeMO, CCS \\
\hline Protection & $\begin{array}{c}\text { Differential and } \\
\text { Magnetic Protections }\end{array}$ & $\begin{array}{c}\text { Differential and } \\
\text { Magnetic Protections }\end{array}$ & Included in the Vehicle & Included in the charger \\
\hline
\end{tabular}


In 2014, a legislation that makes Type 2 plug a standard for AC charging (typically slow charging) was introduced by the European Commission. CCS Combo 2 is a standard for DC charging (fast charging) (Ferwerda et al., 2018).

\section{POWER CONDITIONING SOLUTIONS}

The arrival of new devices - the EV chargers, might bring new disturbances into the power system. In recent years, there have been several studies that touch upon the subject of reducing the negative impact on an electrical grid.

One of the suggested solutions is to design new topologies of the EV chargers (device level). Another idea is the use of passive filters or active power filters which are able to cancel harmonics (power system level) (Guoliang et al., 2013; Khalid et al., 2019; Martínez-Lao et al., 2017). For maintaining the demand supply balance and reducing the losses in the power system, a smart metering method has also been proposed (Galus and Andersson, 2008; Masoum et al., 2010).

The use of renewable energy resources is helpful in decreasing the adverse effects of EV charging process on a power system.

It is also advisable that the charging mode of electric vehicles should match the amount of time an EV is to be parked, as it can minimize the burden on the grid (Spöttle et al., 2018). Mitigation of negative effects of EVs can also be done when $\mathrm{EV}$ is being charged during the off-peak hours (Martínez-Lao et al., 2017).

\section{POWER QUALITY ANALYSIS OF BMW I3}

Power Quality Analyzer SONEL PQM-700 was used for measurement and analysis of the power quality parameters during the slow charging of a BMW i3 electric vehicle with a battery capacity of $60 \mathrm{Ah}$ (the real range of the BMW i3 is approximately $100 \mathrm{~km}$ ), (fig. 2) that was bought by Lublin University of Technology in 2018. C5 clamps were used for the test.

The state of EV charge was $30 \%+$. Nominal phase voltage was $230 \mathrm{~V}$ and the power frequency was $50 \mathrm{~Hz}$. The SONEL PQM-700 device provides its users with comprehensive features for measuring, analysing and recording parameters in accordance with the European Standard EN 50160 (fully compliant with the requirements of IEC 61000-4-30). The BMW i3 uses the CCS charging standard, which consists of a combined $\mathrm{AC}$ and DC input port. In this study, type 2 connector (fig. 3) with a wallbox was used to charge the electric vehicle. Three modes of charging were considered: 11 A (fastest), $8.3 \mathrm{~A}$ (medium) and $5.5 \mathrm{~A}$ (slowest). The EV charger was normally connected to the power distribution network for charging.

According to the IEC 61000-4-30 standard, the following power quality parameters can be distinguished: power frequency, magnitude of supply voltage and current, flicker, supply voltage dips and swells, voltage interruptions, transient voltages, supply voltage and current unbalance, voltage and current harmonics and interharmonics, mains signaling on the supply

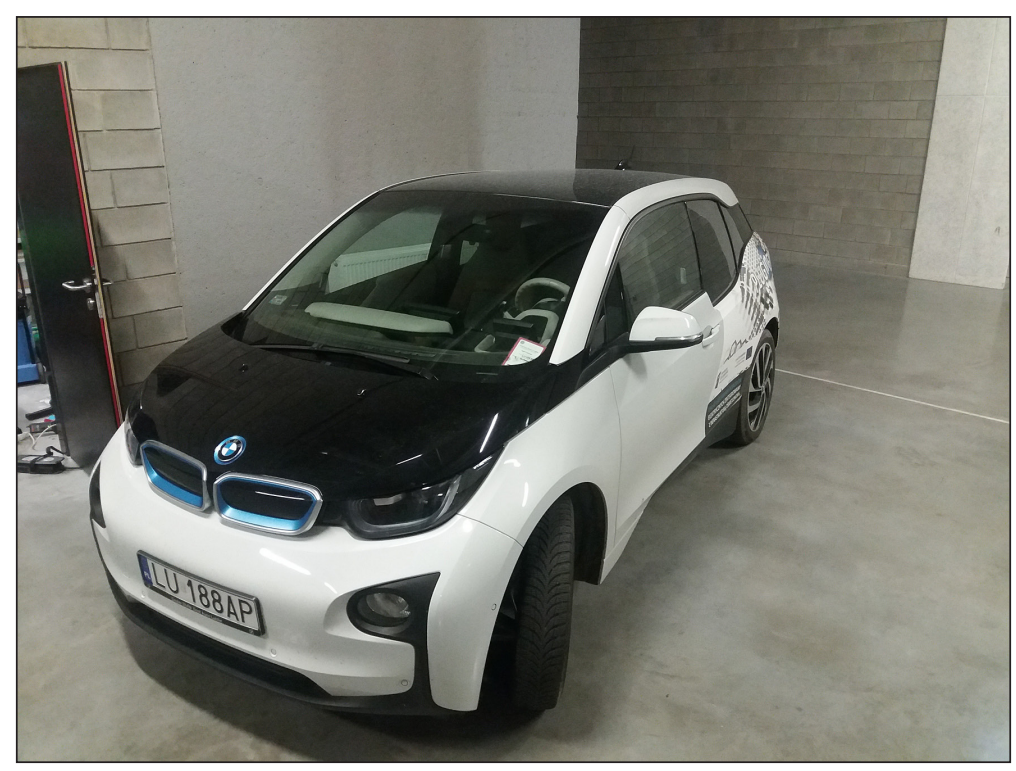

Figure 2. BMW i3 electric vehicle 


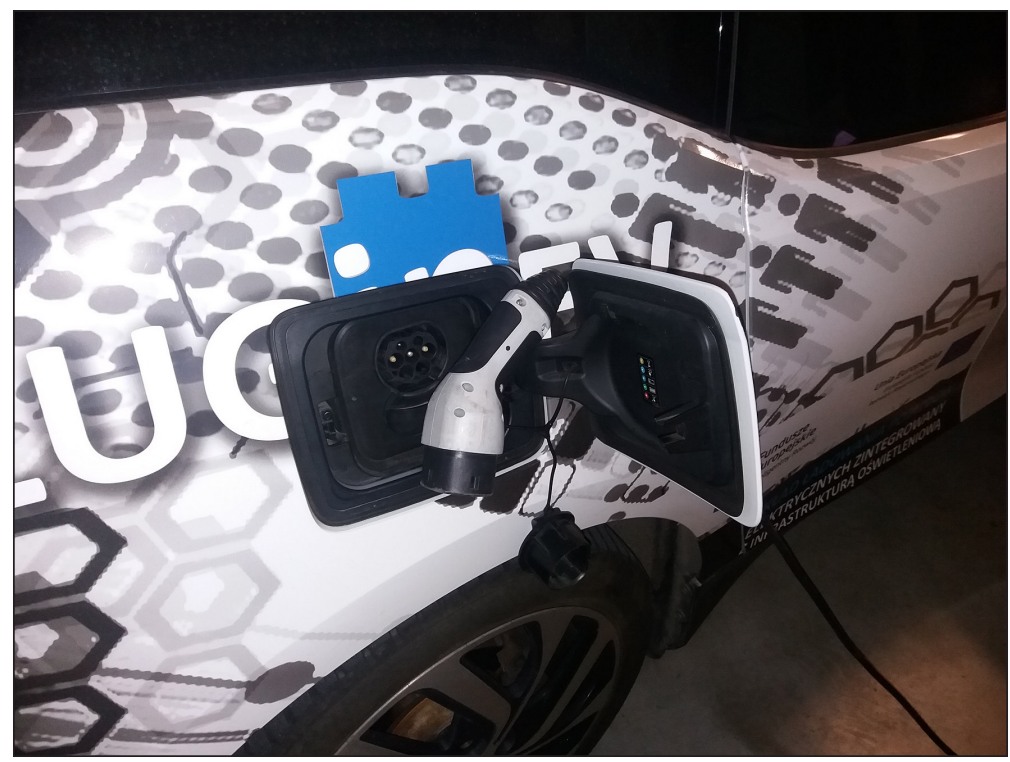

Figure 3. Type 2 connector and CCS socket

voltage, rapid voltage changes, and measurement of underdeviation and overdeviation parameters (IEC 61000-4-30, 2015).

The measurements focus on the values of phase voltage, drawn current, harmonics, values of active, reactive and apparent power. The results are as follows.

\section{Phase voltage and drawn current}

Fig. 4, fig. 5. and fig. 6. show the input voltage and charging current waveforms during different EV charging modes. It can be observed that the current is more distorted when the EV is charged with a lower current. The voltage and current waveforms were sinusoidal.

Power factor $\varphi$ slightly decreases as the drawn current decreases $(\varphi=0.997$ for $11 \mathrm{~A} ; \varphi=0,995$ for $8.3 \mathrm{~A}$ and $\varphi=0.985$ for $5.5 \mathrm{~A}$ ).

\section{Harmonic disturbances}

The analysis pertaining to the impact of EV charging on an electrical grid must consider harmonics as they are disturbances of a power system. A standard EV charger is equipped with $\mathrm{AC}$ to DC converters that directly affect the power quality parameters. Fig. 7. and fig. 8 show the current and voltage harmonic,s respectively. According to IEC 61000-3-2 standard harmonic current emissions were within limits.

The total harmonic voltage distortion $\mathrm{THD}_{\mathrm{v}}$, is defined as:

$$
T H D_{V}=\frac{\sqrt{\sum_{n=2}^{40} V_{n}^{2}}}{V_{1}}
$$

where: $V_{n}$ is the RMS voltage of nth harmonic; $V_{1}$ - voltage of fundamental frequency.

The values produced during EV charging were $1.35 \%, 1,25 \%$ and $1,3 \%$ for charging at $11 \mathrm{~A}, 8.3 \mathrm{~A}$ and $5.5 \mathrm{~A}$ respectively. According to the regulation of the Minister of Economy of 4 May 2007 on detailed conditions for the operation of the power system. THD $_{\mathrm{V}}$ should not exceed $8 \%$ (Regulation of the Minister of Economy dated 4 May 2007 on the detailed conditions for the power system operation (Journal of Laws No. 93, item 623 of 29 May 2007). Table 2 presents total harmonic voltage distortion of different charging modes.

\section{CONCLUSIONS}

Electric vehicles constitute a significant part in the shift towards the society that uses renewable energy (Machura and Li, 2019). The efficiency of the power system is to be maximized when controlled charging of electric vehicles is applied. Raising the awareness connected with the power quality issues and electric vehicles is as important as raising the environmental awareness. Various issues concerning power quality have been highlighted and discussed. 


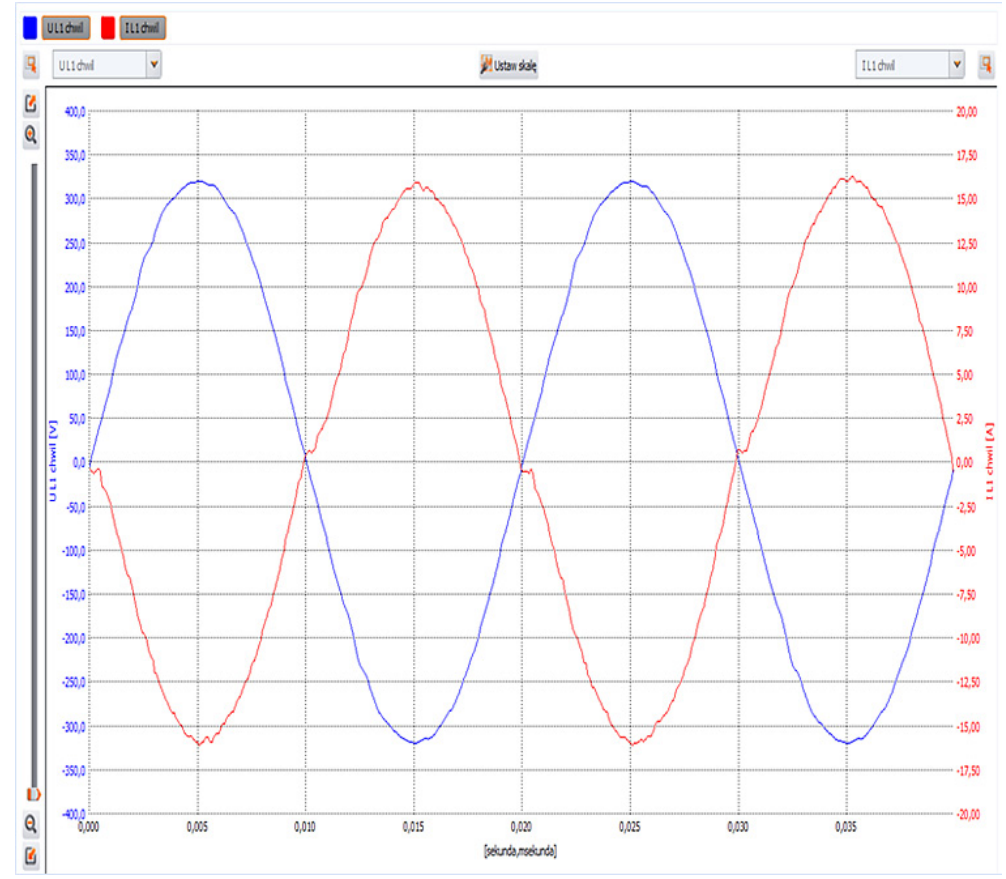

Figure 4. Input voltage (blue) and charging current (red) during EV charging at $\sim 11 \mathrm{~A}(227.9 \mathrm{~V} ; \mathrm{P}=2.497 \mathrm{~kW} ; \mathrm{S}=2.504 \mathrm{kVA})$

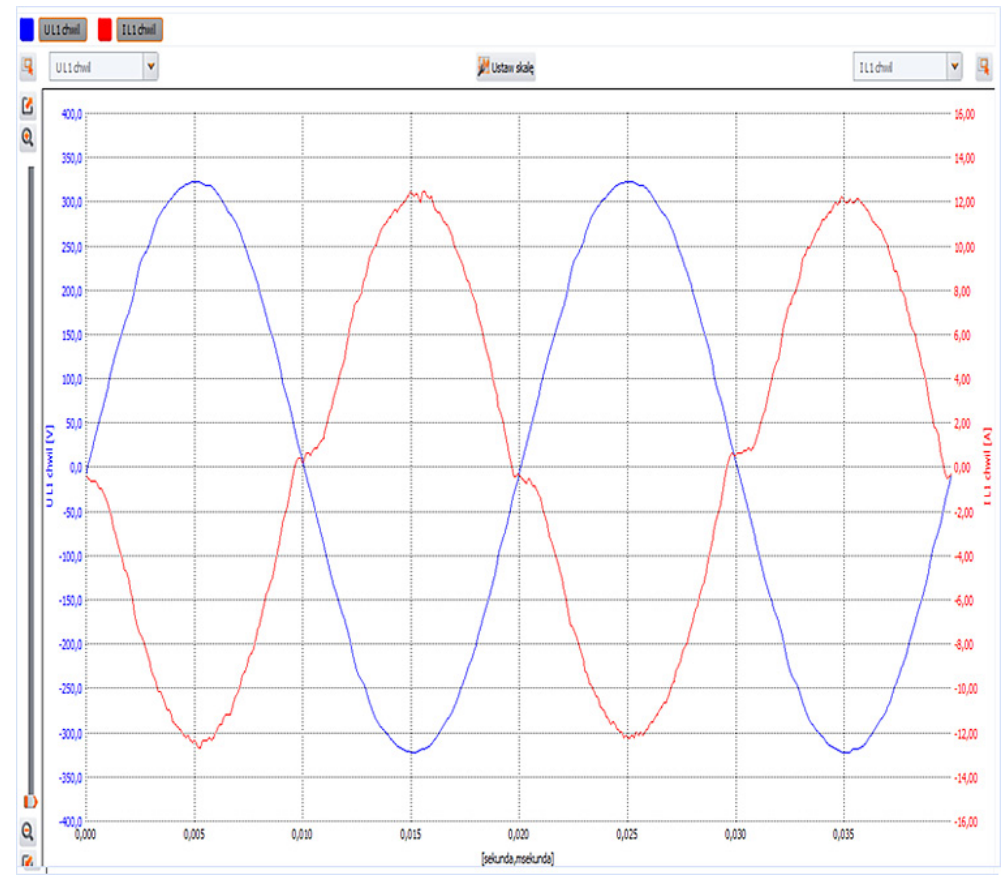

Figure 5. Input voltage (blue) and charging current (red) during EV charging at $\sim 8.3 \mathrm{~A}(229.7 \mathrm{~V} ; \mathrm{P}=1.895 \mathrm{~kW} ; \mathrm{S}=1.889 \mathrm{kVA})$

Power quality affects the operation of a power system and millions of electric devices connected to it; thus, it indirectly affects the safety of people and the environment.

The widespread implementation of electromobility is associated with an increase in electricity demand. Charging of electric vehicles could pose a significant threat to the electrical grid in terms of additional load, unless the load management charging strategies are introduced. An appropriate grid network is crucial for robust and reliable electricity system with multiple charging stations that have multiple charging points. New topologies of battery chargers and application of 


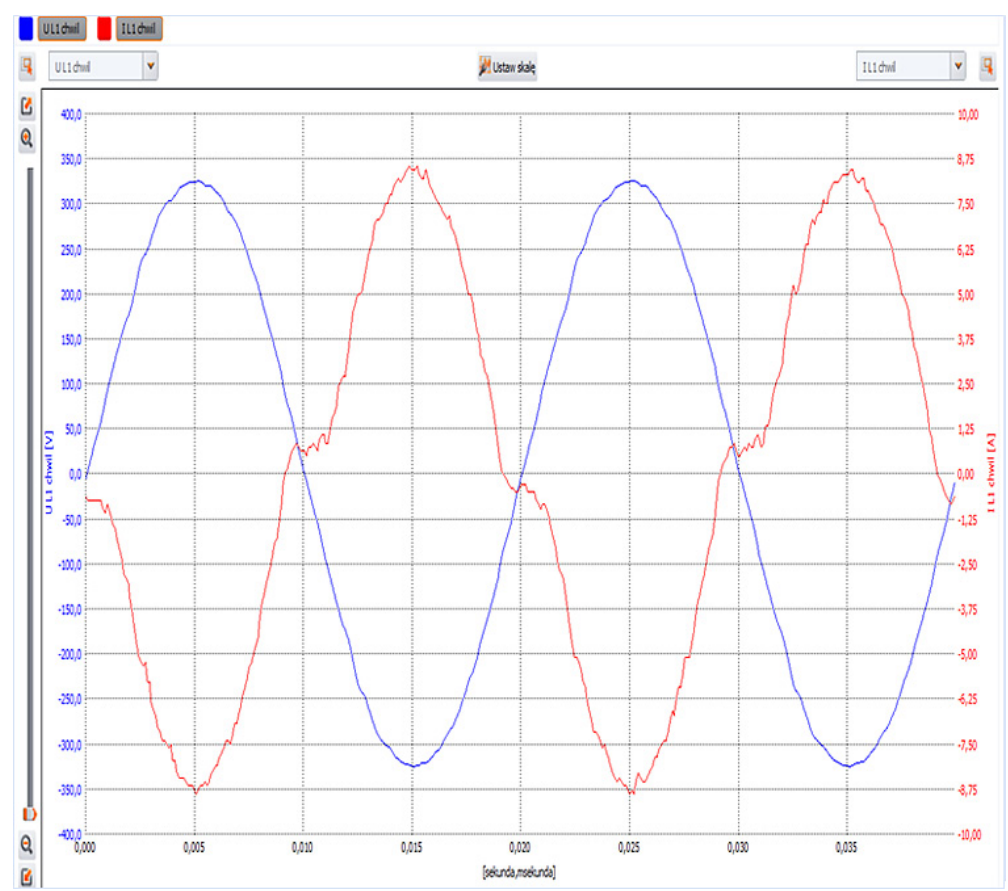

Figure 6. Input voltage (blue) and charging current (red) during EV charging at $\sim 5.5 \mathrm{~A}(231.4 \mathrm{~V} ; \mathrm{P}=1.261 \mathrm{~kW} ; \mathrm{S}=1.28 \mathrm{kVA})$

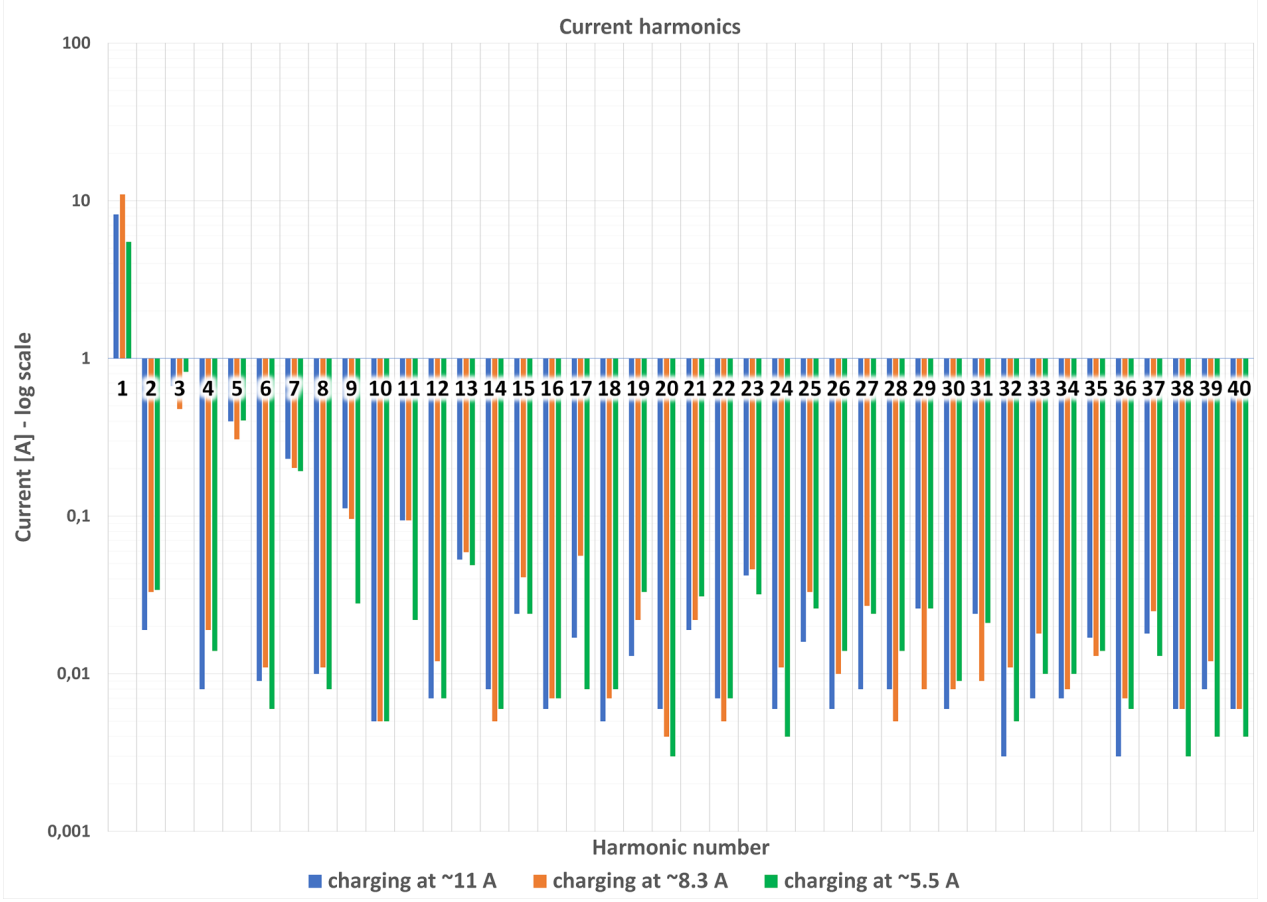

Figure 7. Current harmonics for three modes of EV charging

active power filters can alleviate or almost eliminate the adverse effect of EV charging.

The electrification of transportation contributes to the improvement in the quality of life. Charging stations should be located so that an EV can always have access to them. Long-term planning and implementation of new policies and new regulatory changes are vital for the future of electromobility and reduction of harmful gases that are constantly released to the atmosphere. The study points out the need for the assessment of the power quality performance of an electrical grid of power system with renewable energy resources to which numerous charging stations are connected. 


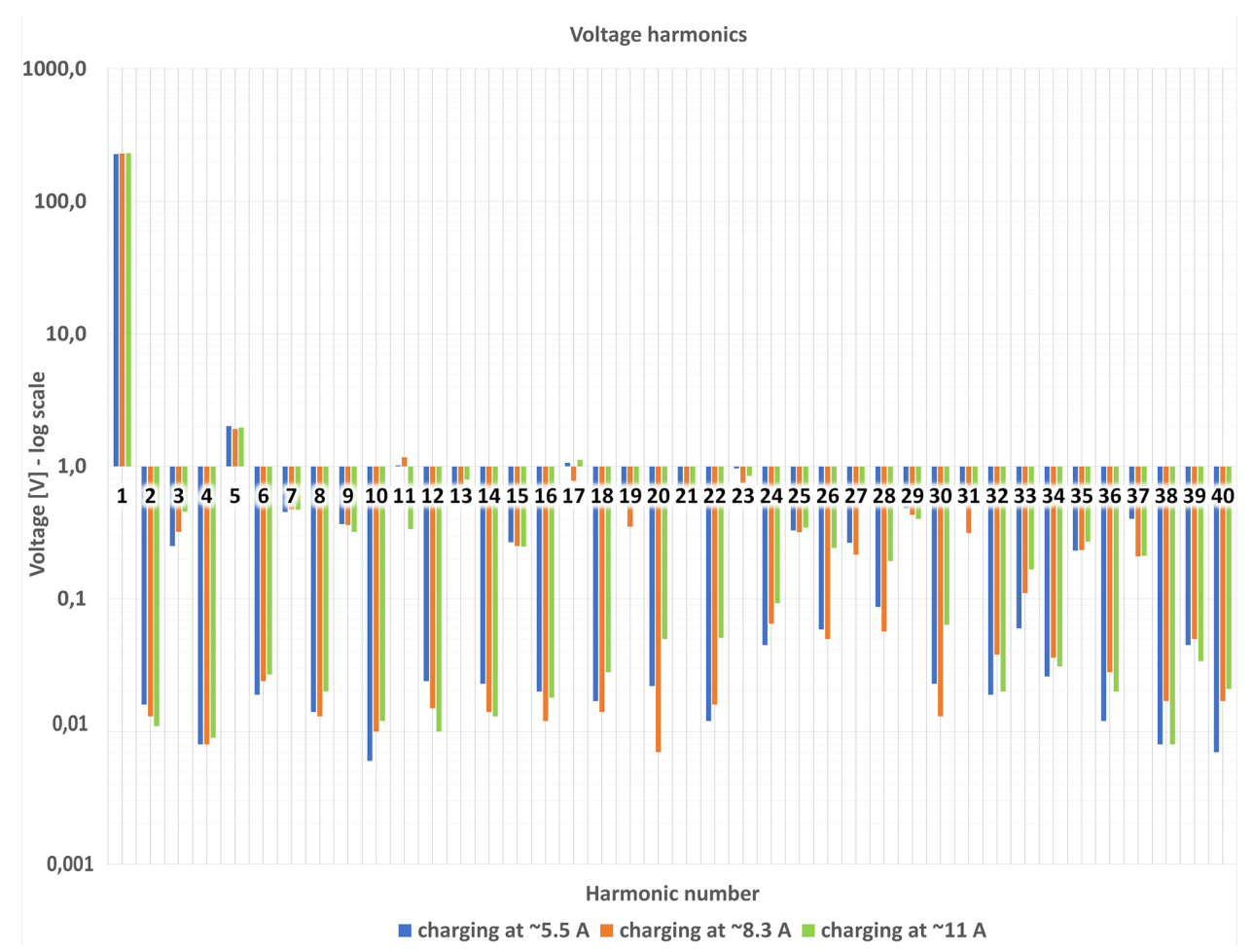

Figure 8. Voltage harmonics for three modes of EV charging

Table 2. Total harmonic voltage distortion of different charging modes

\begin{tabular}{|c|c|c|c|}
\hline $\begin{array}{c}\text { Charging } \\
\text { mode }\end{array}$ & $\begin{array}{c}\text { charging at } \\
\sim 11 \mathrm{~A}\end{array}$ & $\begin{array}{c}\text { charging at } \\
\sim 8,3 \mathrm{~A}\end{array}$ & $\begin{array}{c}\text { charging at } \\
\sim 5,5 \mathrm{~A}\end{array}$ \\
\hline $\mathrm{THD}_{\vee}$ & $1,35 \%$ & $1,25 \%$ & $1,30 \%$ \\
\hline \multicolumn{2}{|c|}{$\mathrm{THD}_{\mathrm{V}}$ limit } & \multicolumn{2}{|c|}{$8 \%$} \\
\hline
\end{tabular}

More power quality measurements of EV systems supply are needed and will be carried out in the future work.

\section{REFERENCES}

1. Broy, A., Sourkounis, C., 2011. Influence of charging electric vehicles and on the quality of the distribution grids, in: 11th International Conference on Electrical Power Quality and Utilisation (EPQU), 2011. 17-19 Oct. 2011, Lisbon, Portugal. IEEE, Piscataway, NJ, pp. 1-4.

2. Can, B., Ayan, O., Silsupur, M., Turkay, B.E., 2016. Harmonic Effects of Electric Vehicles on Low Voltage Distribution Transformers and Power Grid, in: 2nd International Symposium on Multidisciplinary Studies and Innovative Technologies. ISMSIT 2018 : proceedings : 19-21 October 2018, Kizllcahamam/ Ankara/Turkey. IEEE, Piscataway, NJ, pp. 1-6.

3. Colmenar-Santos, A., Muñoz-Gómez, A.-M., Rosales-Asensio, E., López-Rey, Á., 2019. Electric vehicle charging strategy to support renewable energy sources in Europe 2050 low-carbon scenario. Energy 183, 61-74.

4. Falvo, M.C., Sbordone, D., Bayram, I.S., Devetsikiotis, M., 2014. EV charging stations and modes: International standards, in: 2014 International Symposium on Power Electronics, Electrical Drives, Automation and Motion. IEEE, pp. 1134-1139.

5. Ferwerda, R., Bayings, M., van der Kam, M., Bekkers, R., 2018. Advancing E-Roaming in Europe: Towards a Single "Language" for the European Charging Infrastructure. WEVJ 9 (4), 50.

6. Galus, M.D., Andersson, G., 2008. Demand Management of Grid Connected Plug-In Hybrid Electric Vehicles (PHEV), in: 2008 IEEE Energy 2030 Conference. IEEE, pp. 1-8.

7. Gao, Y., Farley, K.B., Ginart, A., Tse, Z.T.H., 2016. Safety and efficiency of the wireless charging of electric vehicles. Proceedings of the Institution of Mechanical Engineers, Part D: Journal of Automobile Engineering 230 (9), 1196-1207.

8. González, L.G., Siavichay, E., Espinoza, J.L., 2019. Impact of EV fast charging stations on the power distribution network of a Latin American intermediate city. Renewable and Sustainable Energy Reviews 107, 309-318.

9. Guoliang, W., Bingliang, X., Haiyang, Y., Eriia, D., 2013. Power quality analysis and harmonic suppression of high latitude and high alpine region electric vehicles charging station, in: 2013 World Electric Vehicle 
Symposium and Exhibition (EVS27). IEEE, pp. 1-5.

10. Hanauer, D., 2018. Mode 2 Charging-Testing and Certification for International Market Access. WEVJ 9 (2), 26.

11. Hou, H., Xie, J., Zhao, D., Chen, W., Li, Z., Ma, J., Meng, K., Dong, Z., 2016. Electrical Vehicle Wireless Charging Technology Based on Energy Internet Application in China. Procedia Computer Science 83, 1332-1337.

12. https://www.tesla.com/model3, 2019. Model 3 | Tesla. 7 August 2019.

13. IEC 61000-4-30, 2015. Electromagnetic compatibility (EMC) - Part 4-30: Testing and measurement techniques - Power quality measurement methods.

14. IEC 61851-1, 2017. Electric vehicle conductive charging system - Part 1: General requirements.

15. Jang, Y.J., 2018. Survey of the operation and system study on wireless charging electric vehicle systems. Transportation Research Part C: Emerging Technologies 95, 844-866.

16. Jiang, C., Torquato, R., Salles, D., Xu, W., 2014. Method to Assess the Power-Quality Impact of Plug-in Electric Vehicles. IEEE Trans. Power Delivery 29 (2), 958-965.

17. Karmaker, A.K., Roy, S., Ahmed, M.R., 2019-2019. Analysis of the Impact of Electric Vehicle Charging Station on Power Quality Issues, in: 2019 International Conference on Electrical, Computer and Communication Engineering (ECCE). IEEE, pp. 1-6.

18. Khalid, M.R., Alam, M.S., Sarwar, A., Jamil Asghar, M.S., 2019. A Comprehensive review on electric vehicles charging infrastructures and their impacts on power-quality of the utility grid. eTransportation $1,100006$.

19. Machura, P., Li, Q., 2019. A critical review on wireless charging for electric vehicles. Renewable and Sustainable Energy Reviews 104, 209-234.
20. Martínez-Lao, J., Montoya, F.G., Montoya, M.G., Manzano-Agugliaro, F., 2017. Electric vehicles in Spain: An overview of charging systems. Renewable and Sustainable Energy Reviews 77, 970-983.

21. Masoum, M.A.S., Deilami, S., Islam, S., 2010-2010. Mitigation of harmonics in smart grids with high penetration of plug-in electric vehicles, in: IEEE PES General Meeting. IEEE, pp. 1-6.

22. Nikitha, L., Anil, L., Tripathi, A., Nagesh, S., 2017 - 2017. Effect of electrical vehicle charging on power quality, in: 2017 International Conference on Circuit, Power and Computing Technologies (ICCPCT). IEEE, pp. 1-6.

23. Regulation of the Minister of Economy dated 4 May 2007 on the detailed conditions for the power system operation (Journal of Laws No. 93, item 623 of 29 May 2007), 2007.

24. Sarker, A., Qiu, C., Shen, H., Gil, A., Taiber, J., Chowdhury, M., Martin, J., Devine, M., Rindos, A.J., 2016. An Efficient Wireless Power Transfer System to Balance the State of Charge of Electric Vehicles, in: 2016 45th International Conference on Parallel Processing (ICPP). IEEE, pp. 324-333.

25. Spöttle, M., Jörling, K., Schimmel, M., Staats, M., Grizzel, L., Jerram, L., Drier, W., Gartner, J., 2018. Research for TRAN Committee - Charging infrastructure for electric road vehicles. European Parliament, [Brussels], 1 online resource (126.

26. Tiano, F.A., Rizzo, G., Marra, D., 2018. Design and Optimization of a Charging Station for Electric Vehicles based on Compressed Air Energy Storage. IFAC-PapersOnLine 51 (9), 230-235.

27. Zhang, W., Mi, C.C., 2016. Compensation Topologies of High-Power Wireless Power Transfer Systems. IEEE Trans. Veh. Technol. 65 (6), 4768-4778.

28. Zhang, Z., Pang, H., Georgiadis, A., Cecati, C., 2019. Wireless Power Transfer-An Overview. IEEE Trans. Ind. Electron. 66 (2), 1044-1058. 